Liu, W., et al., 2020, Onset of permanent Taklimakan Desert linked to the mid-Pleistocene transition: Geology, v. 48, https://doi.org/10.1130/G47406.1

Data Repository for:

\title{
Onset of Permanent Taklimakan Desert Linked to the Mid-Pleistocene
}

\section{Transition}

Liu et al.

This PDF file includes:

DR text

Seven DR figures and captions

One DR table (Table DR1, as a separate excel file) 


\section{DR Text:}

\section{Materials and Methods}

Materials The 1050-m Lop Nur borehole and its geological setting have been thoroughly described in previous publications (Chang et al., 2012; Liu et al., 2014) and stratigraphic column and representative photos are presented here (Figs. DR1A, DR3, DR4). Briefly, the borehole could be divided into four lithological units from the bottom to top (Chang et al., 2012): (I) 1050-800 m: argillaceous limestone intercalated with clay, (II) 800-710 m: clayey silt intercalated with clay, (III) 710-35 m: clayey silt intercalated with silt and clay, and (IV) 35-0 m: massive sand. Thus the core lithology itself roughly reflects paleoenvironmental changes in the basin. In this study, we have conducted $\sim 4300$ carbonate isotopes and $\sim 5250$ grain size analyses, yielding an on-average $<2 \mathrm{kyr}$ sampling resolution. Portion of the carbonate oxygen isotopic data, particularly from the lower lacustrine section (before $\sim 4.9 \mathrm{Ma}$ ), have been reported previously (Liu et al., 2014). High-resolution proxy records from the upper section presented in this study cover the critical interval, onset of permanent desert landscape around the MidPleistocene Transition (MPT).

Chronology The chronology of the Lop Nur borehole was established previously based on paleomagnetic polarity (Chang et al., 2012). Briefly, remanence was measured using a $2 \mathrm{G}$ cryogenic superconducting magnetometer (model 755R) and most samples yielded a stable characteristic remnant magnetization component. The total 706 remanence measurements on the continuous sediment profile allow straightforward correlation with the CK95 geomagnetic polarity timescale (GPTS) (Cande and Kent, 1995). Identified 14 normal (N1-N14) and 13 reversal (R1-R13) polarity zones could be correlated to magnetic polarity from $C 1 n$ to $C 3 B n$, covering the last 7.1 Myr (Fig. DR1A). The CK95 timescale is largely consistent (within a few 
thousands of years, kyrs) with that inferred from marine archives (Lisiecki and Raymo, 2005) over the last $5 \mathrm{Myr}$, allowing our discussion of the desertification history in the Tarim Basin under a global context. The derived sedimentation rate is $\sim 200 \mathrm{~m} / \mathrm{Myr}$ before $1.77 \mathrm{Ma}$ and $\sim 40$ $\mathrm{m} / \mathrm{Myr}$ after.

The chronology of the lower and upper Mazartag sections followed Sun et al. (2017) and Pei et al. (2011) respectively (Fig. DR1B, DR1C). The original chronology of the lower Mazartag section (Sun et al., 2009) has been modified based on an alternative correlation of paleomagnetic polarities, shifting this section to much older late Oligocene-Miocene age (Zheng et al., 2015). However, the newly discovered mammal fossil Plesiohipparion (6-3.4 Ma) from this section (Sun et al., 2017) strongly supports the originally proposed chronology (Sun et al., 2009), which is adopted here. The upper section studied is about $1 \mathrm{~km}$ away from the lower section and sediments were not exposed in between (Pei et al., 2011). Three identified normal magnetic polarity zones were correlated with the Jaramillo, Olduvai and Reunion events, constraining the studied section aged between $0.1 \mathrm{Ma}$ and $1.6 \mathrm{Ma}$ (Fig. DR1B). Lastly, all the magnetic polarity zones were correlated to the CK95 timescale (Cande and Kent, 1995) in original publications (Sun et al., 2009; 2017; Pei et al., 2011) and not updated to the GPTS2012 timescale (Gradstein et al., 2012). The difference between the two timescales over the critical interval (last $5 \mathrm{Myr}$ ) is minor and would not affect our interpretation and conclusion here.

Isotope and Grain Size Analyses Prior to carbonate isotope analysis, $\sim 5 \mathrm{~g}$ sediment samples were ground in an agate mortar and sieved through a 100 mesh $(150 \mu \mathrm{m})$ screen. Analyses of carbonate samples were performed using an isotope ratio mass spectrometer (MAT-252) with an automated carbonate preparation device (Kiel II) at the Institute of Earth Environment, Chinese Academy of Sciences, Xi'an. Oxygen and carbon isotope results are expressed in the delta $(\delta)$ 
notation relative to the V-PDB standard. Repeated analyses of laboratory carbonate standards with known $\delta^{18} \mathrm{O}$ and $\delta^{13} \mathrm{C}$ values were performed daily to ensure instrumental accuracy. Typical standard deviation for the repeated analyses of these laboratory standards is smaller than $\pm 0.1 \%$.

For grain size analysis, all samples were pretreated by $10 \% \mathrm{H}_{2} \mathrm{O}_{2}$ and $10 \% \mathrm{HCl}$ in order to remove of organic matter and carbonates. Then samples were filled with distilled water and kept overnight in beakers. Prior to grain-size measurements, water was siphoned off and samples were dispersed by ultrasonification in $10 \mathrm{ml} 10 \%\left(\mathrm{NaPO}_{3}\right)_{6}$ solution for 10 minutes. Grain-size distributions were finally determined using a Malvern 2000 laser instrument. Modal size, the mostly frequently occurring particle size, is mainly used to illustrate particle size changes over the past 7.1 Myr.

$\delta^{13} C_{\text {carb }}$ and Grain Size Interpretation The interpretation of carbonate $\delta^{13} \mathrm{C}$ signal from nonlacustrine, relatively less vegetated settings is rather straightforward. Paleosol carbonate $\delta^{13} \mathrm{C}$ has been widely used to indicate paleovegetation and paleoenvironmental changes, however, $\delta^{13} \mathrm{C}$ signals from the primary detritus carbonate must be considered and only $\delta^{13} \mathrm{C}$ values of secondary carbonate in paleosol can be used for paleoclimate and paleoenvironment studies (Cerling, 1999). Detrital carbonates in eolian and fluvial deposits in arid regions of northwestern China mainly originate from ancient weathered marine carbonates in nearby regions (Liu et al., 2014), which have relatively constant oxygen isotope $\left(\delta^{18} \mathrm{O}_{\text {carb }}, \sim-8 \%\right.$ o $)$ and carbon isotope $\left(\delta^{13} \mathrm{C}_{\mathrm{carb}}, \sim 0 \%\right.$ o) values, and thus fulfill this requirement. $\delta^{13} \mathrm{C}_{\mathrm{carb}}$ in these deposits effectively reflect the degree of biologically and chemically controlled secondary carbonate added to the background signal and thus regional vegetation cover and biological productivity in the arid and semi-arid regions. 
Further, $\delta^{13} \mathrm{C}_{\text {carb }}$ values in surface sediments on the arid northwestern Chinese Loess Plateau (CLP) show strong correlations with both mean annual rainfall and temperature (Sun et al., 2015) (Fig. DR2). In the CLP loess-paleosol sequence, $\delta^{13} C_{\text {carb }}$ values also closely followed $\delta^{13} \mathrm{C}$ values in total organic carbon (Liu et al., 2010). Therefore $\delta^{13} \mathrm{C}_{\text {carb }}$ values could be eventually linked to vegetation amount/density, and become progressively negative with the input of soil organic carbon during soil pedogenesis/respiration. In the surface soil study (Sun et al., 2015), $\delta^{13} \mathrm{C}_{\text {carb }}$ shows a stronger correlation with precipitation than temperature (Fig. DR2). However, in this study, we use $\delta^{13} \mathrm{C}_{\text {carb }}$ values to infer vegetation amount/density (and thus the desert landscape with minimal vegetation cover), without separating precipitation and temperature effects.

The $\delta^{13} \mathrm{C}_{\text {carb }}$ record from our Lop Nur borehole does not show obvious changes when lacustrine phase vanished around $\sim 4.9$ Ma, while the Mazartag profile does (Fig. 2B). We interpret that the $\delta^{13} \mathrm{C}_{\text {carb }}$ values were additionally affected by the strong enrichment effect from lake water evaporation as Lop Nur, currently at the lowest elevation ( $\sim 800 \mathrm{~m}$ above sea level), was probably at the lake center. The lacustrine phase before $\sim 4.9$ Ma can be confirmed by other proxies such as boron and oxygen isotopes (Liu et al., 2014). In the early part of the Lop Nur borehole record, $\delta^{18} \mathrm{O}_{\text {carb }}$ displays large amplitude of variability $(>10 \%)$, due to strong lake evaporation processes, thus demonstrating the existence of episodic lakes in the late Mioceneearly Pliocene period (Liu et al., 2014). However, it remains at $\sim-8 \%$ after lacustrine phase disappeared and thus appears to be not particularly sensitive to reflect paleoenvironmental changes in non-lacustrine settings (Fig. 2D). After vanishing of episodic lakes at $\sim 4.9 \mathrm{Ma}$, $\delta^{13} \mathrm{C}_{\text {carb }}$ values could faithfully indicate vegetation cover in the Tarim Basin. 
In the upper Mazartag section, $\delta^{13} \mathrm{C}_{\text {carb }}$ values appear to be exceptionally negative (Pei et al., 2011) (Fig. 2B, DR5). Its average value is more negative than that at Lop Nur for the same time period and the one in the lower Mazartag section (Fig. 2B). This might be simply due to interlab analytical uncertainty as the rest of $\delta^{13} \mathrm{C}_{\text {carb }}$ data were generated from the same lab. However, based on lithological descriptions of the upper Mazartag section, lacustrine deposits re-appeared from $\sim 1.6$ to 1.0 Ma. Hence, it was plausible that a localized, shallow lake existed along the uplifted Mazartag Mountain, which would not represent the basin-wide landscape. Nevertheless, similar pattern of $\delta^{13} \mathrm{C}_{\text {carb }}$ changes in both profiles indicates continued drying, and increased $\delta^{13} \mathrm{C}_{\text {carb }}$ values $(\sim-1 \%$ ) since $\sim 0.4$ Ma based on the original chronology (Pei et al., 2011) are close to those derived from desert landscape, consistent with our interpretation of the onset of the permanent desert landscape around that time.

Grain size of eolian deposits is commonly used to infer wind intensity, although it may be additionally affected by changes in the source region (area and aridity) and the distance from source to sink (Sun et al., 2010). In particular, the occurrence of eolian sand layer is often used as an indicator of desert formation (Sun et al., 2006; 2009; Zheng et al., 2015; Heermance et al., 2018). However, the modal size of eolian sand could be similar to that of fluvial deposits (Heermance et al., 2018). Grain size distributions also display complex features between alternations of lacustrine and eolian deposits (Liu et al., 2014). Hence, additional evidence is needed to assess its eolian origin before using the sand size as an indicator of desert formation (e.g. Heermance et al., 2018). Here, we use modal size together with $\delta^{13} \mathrm{C}_{\text {carb }}$ (vegetation cover) to infer desert formation.

\section{Additional References Cited}

Cande, S.C., and Kent, D.V., 1995, Revised calibration of the geomagnetic polarity time scale 
for the Late Cretaceous and Cenozoic: Journal of Geophysical Research, v. 100, p. 60936095.

Gradstein, F.M., Ogg, J.G., Schmitz, M., and Ogg, G., eds., 2012, The Geologic Time Scale 2012: Amsterdam, Elsevier, 1176 p.

Cerling, T.E., 1999, Paleorecords of $\mathrm{C}_{4}$ plants and ecosystems in: $\mathrm{C}_{4}$ Plant Biology, Sage, R.F., and Monson, R.K., eds. San Diego, Academic Press, p. 445-469.

\section{DR Figure Captions}

Fig. DR1. Stratigraphic columns and age assignments based on paleomagnetic correlations following original publications.

Fig. DR2. Correlation of $\delta^{13} \mathrm{C}_{\text {carbvalues in modern sediments with mean annual rainfall (MAP) }}$ and mean annual temperature (MAT) on western Chinese Loess Plateau.

Fig. DR3. Detailed changes around the onset of permanent desert landscape.

Fig. DR4. Representative core photos presented at approximately every 100 meters.

Fig. DR5. Comparison of $\delta^{13} \mathrm{C}_{\text {carb }}$ changes over the last $2 \mathrm{Myr}$ from the Lop Nur borehole and Mazartag section.

Fig. DR6. Spectral analysis of $\delta^{13} \mathrm{C}_{\text {carb }}$, modal size, and $\delta^{18} \mathrm{O}_{\text {carb }}$ over the whole study period.

Fig. DR7. Detailed view of SST from ODP $846, \delta^{13} \mathrm{C}_{\text {carb }}$ and modal size from Lop Nur borehole, and magnetic susceptibility from Chinese Loess Plateau.

Table DR1. Carbonate oxygen and carbon isotope and grain size (mode) data from the borehole at Lop Nur, provided with a separate file in excel format. 


\section{DR Figures:}

A Lop Nor Borehole

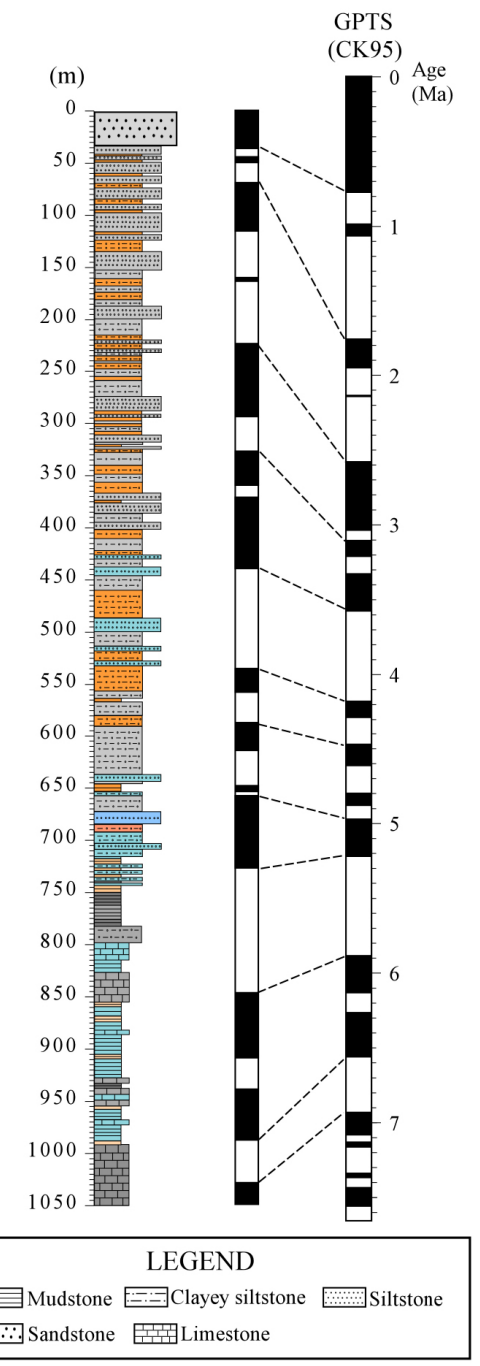

B Mazartag Section A

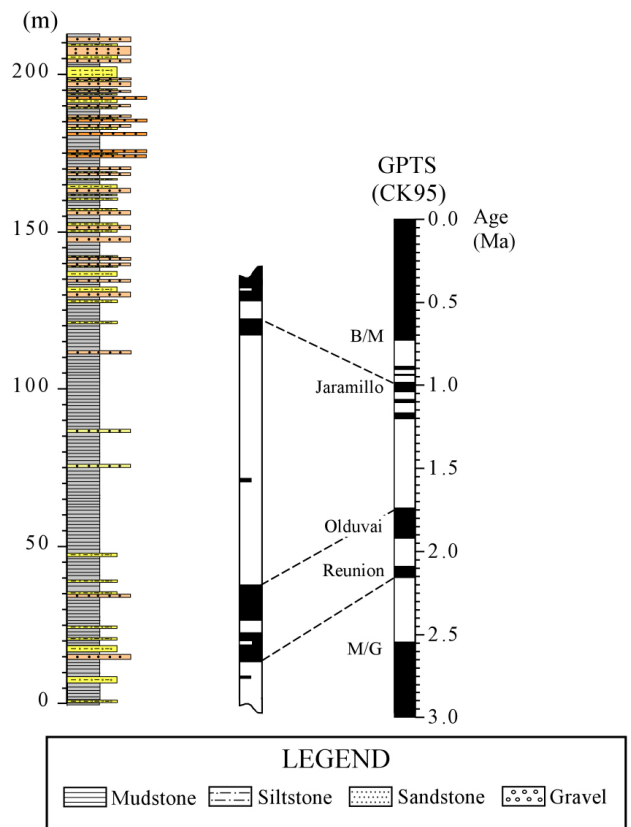

C Mazartag Section B

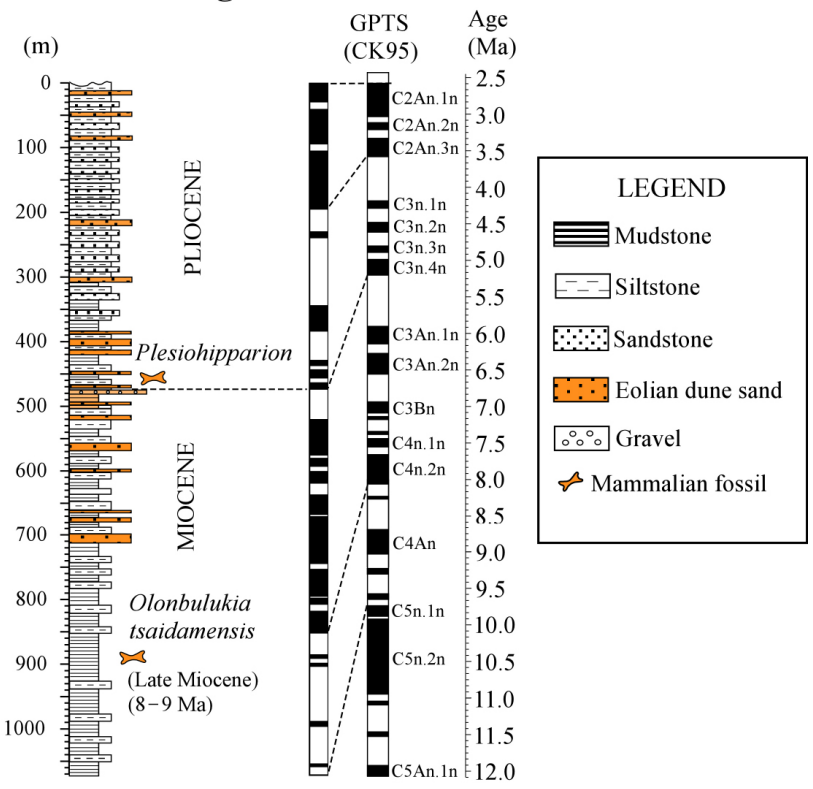

Fig. DR1 Stratigraphic columns and age assignments based on paleomagnetic correlations following original publications. A, Lop Nur borehole (Chang et al., 2012). B, Mazartag, upper section A (Pei et al., 2011). C, Mazartag, lower section B (Sun et al., 2017). 

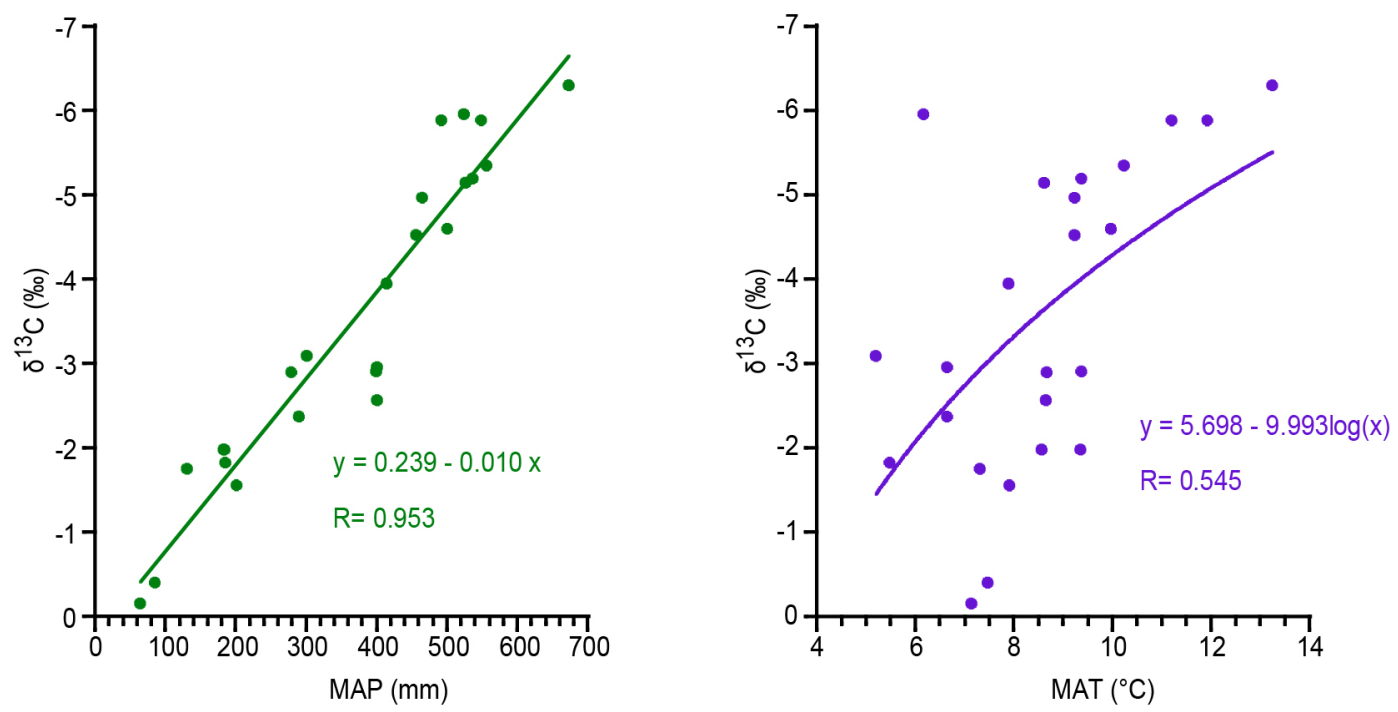

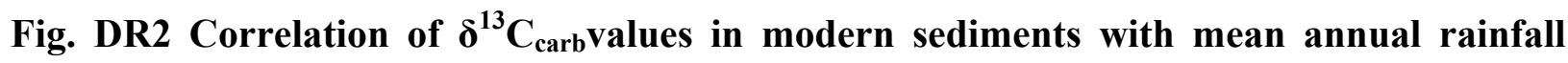
(MAP) and mean annual temperature (MAT) on western Chinese Loess Plateau. Data from Sun et al. (2015) with additional unpublished data. 


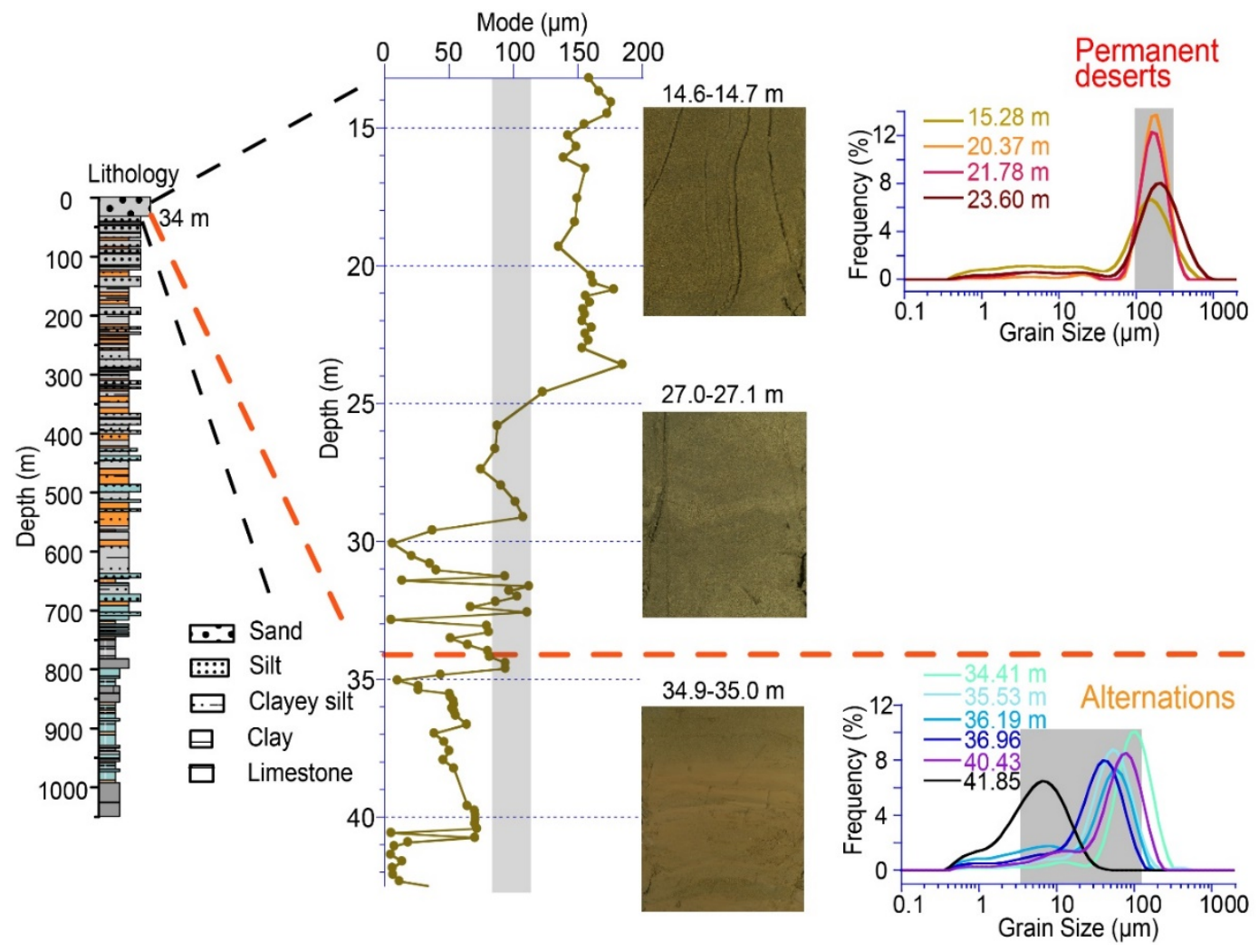

Fig. DR3 Detailed changes around the onset of permanent desert landscape. Shown are representative photos, modal size, and grain size distributions before and after the onset. Grain size distribution above $\sim 23 \mathrm{~m}$ is similar to modern one. 


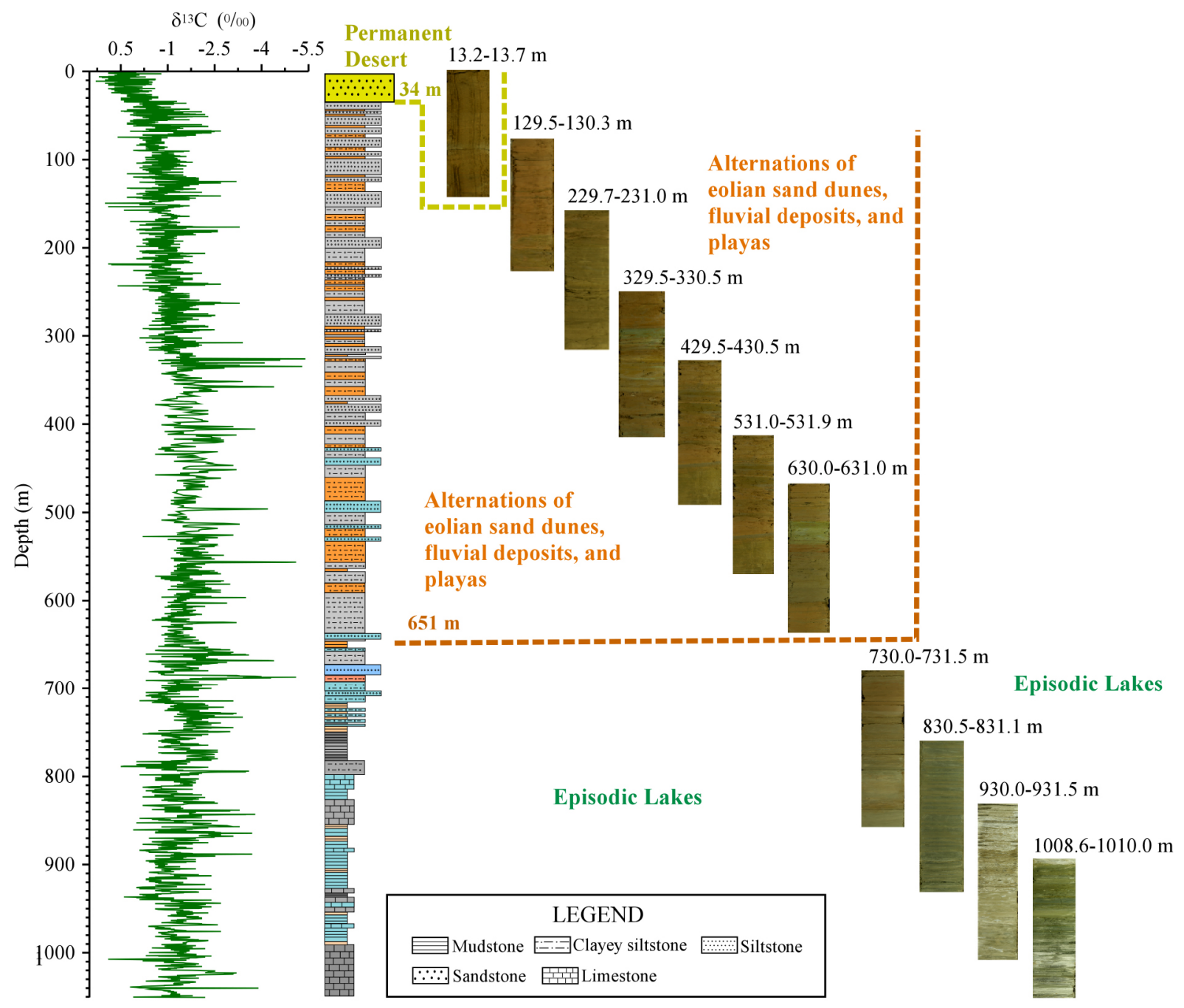

Fig. DR4 Representative core photos presented at approximately every 100 meters. Shown together with stratigraphic column and $\delta^{13} C_{\text {carb }}$ changes against depth scale. Three stages of desert evolution in the Tarim Basin can be visually identified. 




Fig. DR5 $\delta^{13} \mathrm{C}_{\text {carb }}$ changes over the last 2 Myr from the Lop Nur borehole and Mazartag section (Pei et al., 2011). Dashed lines indicate their possible correlations based on pattern of changes in the two $\delta^{13} \mathrm{C}_{\text {carb }}$ records. 

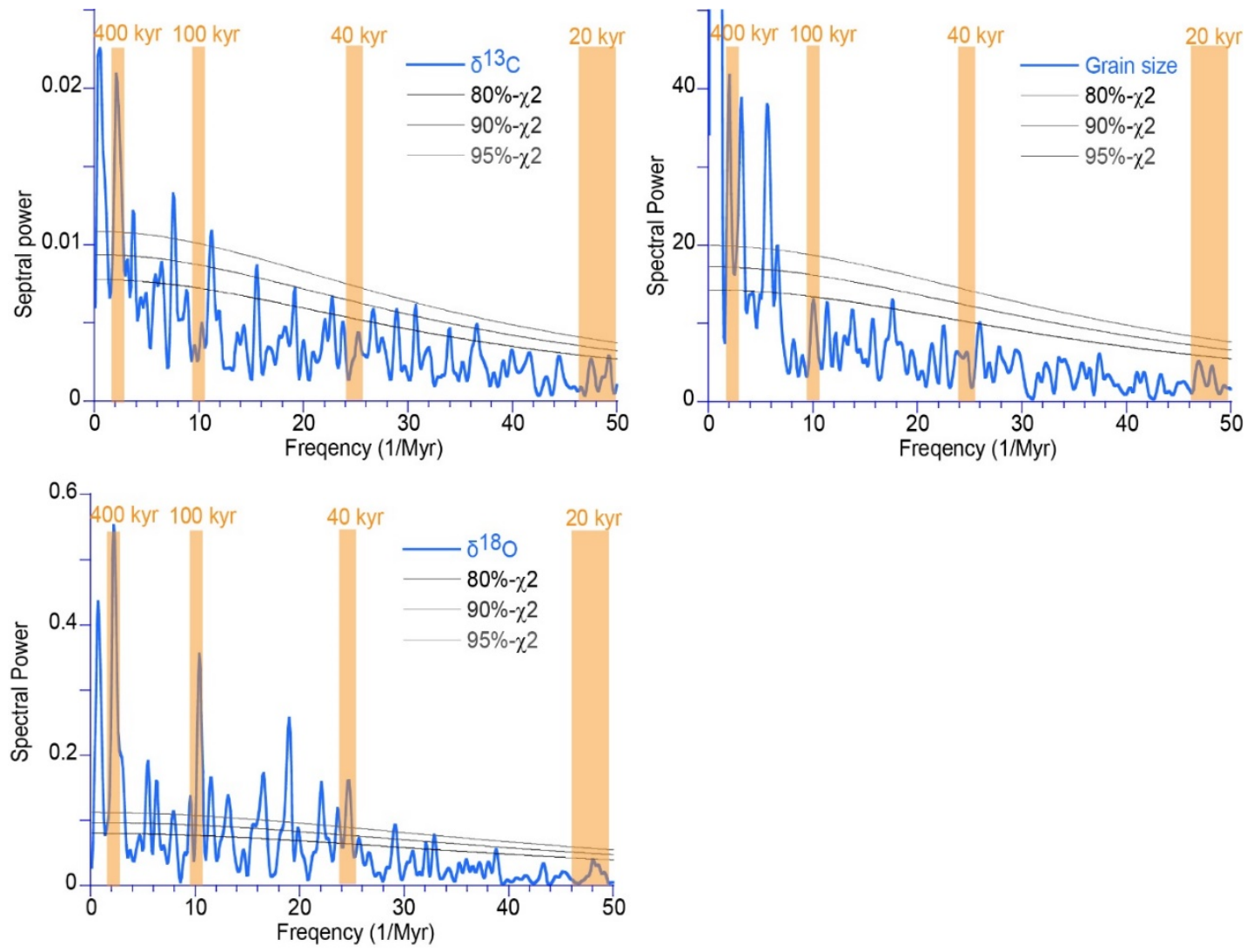

Fig. DR6 Spectral analysis of $\delta^{13} C_{\text {carb }}$, modal size, and $\delta^{18} O_{\text {carb }}$ over the whole study period. Orbital bands are highlighted and the $\sim 400-k y r$ variability is particularly evident. 

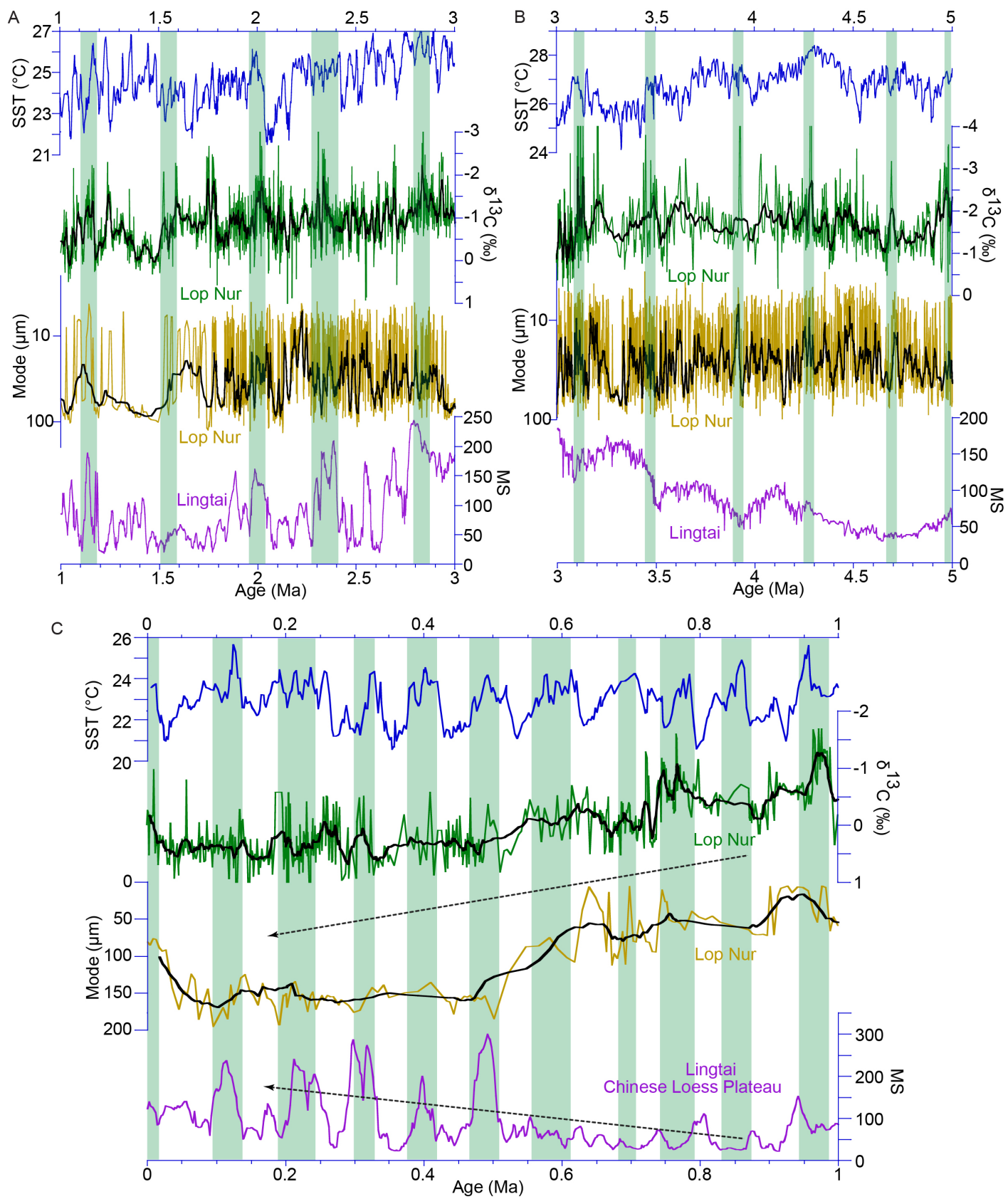

Fig. DR7 Detailed view of SST from ODP 846, Eastern Equatorial Pacific (Herbert et al., 2010), $\delta^{13} C_{\text {carb }}$ and modal size from Lop Nur borehole, and magnetic susceptibility from Lingtai section, Chinese Loess Plateau (Sun et al., 2010). A, 1-3 Ma. B, 3-5 Ma. C, 0-1 Ma. Intervals of substantially more negative $\delta^{13} \mathrm{C}_{\text {carb }}$ values in $\mathrm{A}$ and $\mathrm{B}$, and interglacial periods in $\mathrm{C}$, were highlighted. Black lines indicate 10 -point running average for $\delta^{13} C_{\text {carb }}$ and modal size. 